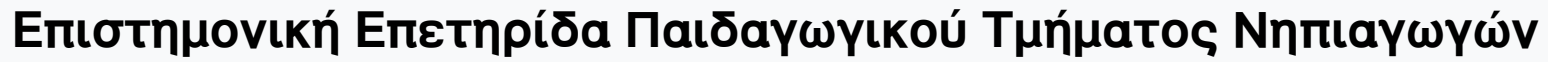 חavertotnuíou Iwavvívwv
}

Tóp. 6 (2013)

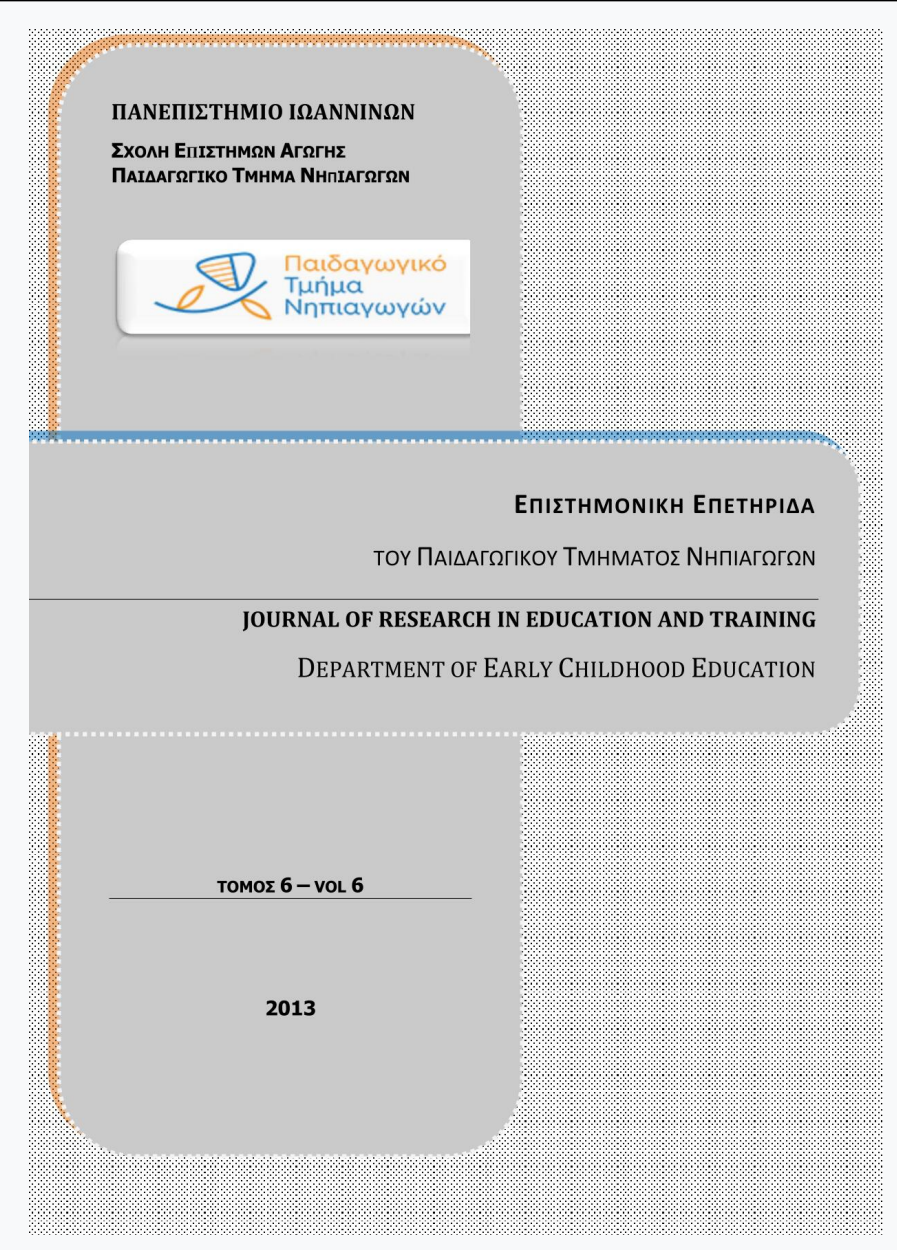

Exploring academic hardiness in Greek students: Links with achievement and year of study

Spiridon Kamtsios, Evangelia Karagiannopoulou

doi: $10.12681 /$ jret.762

Copyright @ 2013, Spiridon Kamtsios, Evangelia Karagiannopoulou

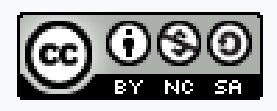

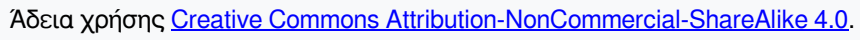

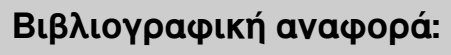

Kamtsios, S., \& Karagiannopoulou, E. (2013). Exploring academic hardiness in Greek students: Links with achievement

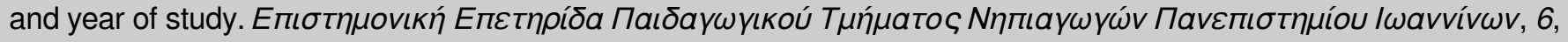
249-266. https://doi.org/10.12681/jret.762 


\title{
Exploring academic hardiness in Greek students: Links with achievement and year of study.
}

\section{Kamtsios Spiridon \& Karagiannopoulou Evangelia}

\begin{abstract}
The purpose of the study was two-fold: a) to investigate the psychometric properties of the revised Academic Hardiness Scale (R-AHS) in the Greek educational content and b) to investigate relationships between academic hardiness, achievement and year of study in Greek undergraduates. A total of 478 undergraduates completed the R-AHS. Findings from exploratory factor analysis revealed three factors (commitment, control and challenge) accounting for $38.65 \%$ of the total variance. High reliability coefficients were obtained for the R-AHS factor scores. The final instrument contains 38 questions. The results of the study indicate a relation between academic hardiness and grade point average (GPA was the academic performance criterion). Commitment was most highly positively correlated with academic achievement. Across the years of study, students appeared less committed and less likely to perceive academic demands as challenge. The findings are discussed in the context of the recent literature.
\end{abstract}

KEY-WORDS: academic hardiness, grade point average, hardiness, undergraduates. 


\section{Introduction}

Over the past two decades, the hardiness construct has received considerable attention as a personality variable which potentially moderates the effects of stress on physical health (Florian, Milkulincer, \& Taubman, 1995; Green, Grant, \& Rynsaardt, 2007; Kobasa, 1979; Kobasa, Maddi, \& Kahn, 1982; Kobasa, Maddi, Puccetti, \& Zola, 1985; Maddi, 2006; Sheard, 2009; Paleologou, \& Dellaporta, 2010). Introduced by Kobasa (1979), hardiness is considered a personality style consisting of the interrelated orientations of commitment (vs alienation), control (vs power-less) and perception of life changes and demands as a challenge (vs threat). If you are strong in commitment you believe it is important to remain involved with the events and people around you, no matter how stressful things becomes. It seems like waste of time to withdraw into alienation and isolation. If you are strong in control, you want to continue to have an influence on the outcomes going on around you, no matter how difficult this become. It seems like a mistake to let yourself slip into powerlessness and passivity. If you are strong in challenge, you see stresses as a normal part of living, and an opportunity to learn, develop, and grow in wisdom. You do not believe that easy comfort and security is a birthright (Maddi, 2006). These various beliefs and tendencies are considerably very useful in coping with stressful events, as these $3 \mathrm{Cs}$ of hardy attitudes provide the courage and the motivation to do the hard work of turning stressful circumstances from potential disasters into growth opportunities (Maddi, 2005, 2006).

Over the past 20 years, the psychological hardiness construct has emerged as a buffer in the relationship between stressors and illness and has been shown to enhance performance in different age and occupational groups (Maddi, 2006). The positive influence of hardiness on undergraduates has also been reported in many recent studies. A range of studies has demonstrated the importance of hardiness for adjustment to university life (Lifton, Seay, McCarly, Olive-Taylor, Seeger, \& Bighee, 2006). Hardiness has been shown to be a predictor in performance effectiveness in college students (Maddi, 2002; Maddi, Harvey, Khoshaba, Fazel, \& Recurreccion, 2011). It has been positively related with retention rate and creativity among college student (Lifton, Seay, \& Bushke, 2000) and negatively associated with both academic stress and a number of health complaints in undergraduates (Hystad, Eid, Laberg, Johnsen, \& Bartone, 2009). Cole, Field and Harris (2004) speculate that students who report having hardy attitudes will be more motivated to learn class material and 
more strongly commitment to their classes than those reporting not having hardy attitudes. Also they propose that hardiness and learning motivation will interact to predict students' affective reactions. Sheard and Golby (2007) particularized and extended the behavioral manifestations of the three hardiness attitudes to the higher education environment. They mentioned that undergraduates with hardy attitudes will show an action pattern of coping with stressful circumstances in the university (e.g. examinations, meeting course work deadline) by facing them, and striving to turn them from potential disasters into opportunities for self.

Given evidence that psychological hardiness helps insulate individuals and undergraduates from the effects of stress and predicts future well-being, questions naturally arise regarding its generability and its influence on outcomes across other contexts (Cole et al., 2004). Initially Benishek and Lopez (2001) tried to investigate the positive impact that hardiness may have in academic settings. Using terminology consistent with hardiness theory they corresponded hardiness attitudes to academic environment. Commitment was defined as students' reported willingness to expend consistent effort and to engage in personal sacrifices in order to achieve academic excellence, irrespective of the content or demands of individual courses, instructors or personal interests (Benishek, Feldman, Shipon, Mecham, \& Lopez, 2005). High commitment students become deeply involved in their studies, seeing this as the best way to turn whatever they are experiencing into something that seems interesting, worthwhile, and important (Sheard \& Golby, 2007). Control concerned students' beliefs that they possessed the capacity to achieve desired educational outcomes from personal effort and through effective emotional self-regulation in the face of academic stresses and disappointments (Benishek et al., 2005). High control students are able to manage their studies demonstrating good time management, prioritizing those activities deemed most contributory to academic success and taking responsibility for their own learning and development (Sheard \& Golby, 2007). Challenge was defined as the students' purposeful efforts to seek out difficult academic coursework and experiences and to justify such actions as inherently for personal learning (Benishek et al., 2005). High challenge students appraise potentially stressful situations as exciting and stimulating than threatening (Sheard \& Golby, 2007). This conceptualization guided the development of the initial version of the Academic Hardiness Scale (AHS) (Benishek \& Lopez, 2001) and the revised version of the Academic Hardiness Scale (R-AHS) (Benishek et al., 2005). 
The Academic Hardiness Scale has been used in research with late elementary school children (Kamtsios \& Karagiannopoulou, 2011), high school students and undergraduates (Golightly, 2007; Karimi \& Venkatesan, 2009; Kinder, 2008). However, only few studies have explored the factorial validity of the scale (Golightly, 2007; Kamtsios \& Karagiannopoulou, 2011). Golightlys' results from the principal component analysis (PCA) in an undergraduate sample indicated a three factor model and the results of the study made by Kamtsios and Karagiannopoulou (2011) in late elementary school children, partially support the validity and reliability of the scale indicating a clear three-factor structure and acceptable reliability coefficients, although low comparing to the original study by Benishek et al. (2005). Some other studies reported psychometric weakness of the scale (Golightly, 2007; Kamtsios \& Karagiannopoulou, 2011). Besides, Benishek et al. (2005) hypothesized that students reporting higher levels of academic hardiness would be more likely to report higher great point average (GPA) scores. Their hypothesis was only partially supported as their findings suggested a significant correlation between GPA scores and challenge. Unexpectedly, correlation coefficients between commitment/control and GPA scores were inversely related to one other. A later study indicated that academic hardiness was correlated with higher grade point average (GPA) scores in undergraduates (Sheard \& Golby, 2007).

Given that there is a long standing interest in understanding of why some students choose challenging academic courses, adopt behaviors that help them to overcome difficult academic courses and modulate their emotional reactions when they fail to achieve their educational goals, we consider that it is important to explore the psychometric properties of the Academic Hardiness Scale in a Greek sample of undergraduate students. Furthermore, the purpose of the study is to investigate the relationship between academic hardiness and its dimensions (commitment, control, challenge) with undergraduates' GPA (Grade Point Average) and to explore possible differences in academic hardiness dimensions reported by students at different years of study. We hypothesize that undergraduates who scored high in academic hardiness will report a higher GPA and that it will be a reduction in the dimensions of hardiness as students' progress through their studies. 


\section{METHOD}

\section{Participants}

A convenience sample of 478 undergraduates ( 66 boys and 412 girls ${ }^{59}$ ), studying in a Social Science Department (University of Ioannina), participated in the study. They were asked to complete the Revised Academic Hardiness Scale (R-AHS) (Benishek et al., 2005) during a lecture class. Their participation was voluntary. The study does not focus on the $1^{\text {st }}$ year students. Participants should have experienced a great deal of the academic culture/context in order to be able to answer questions, included in the scale, about the ways they cope with academic demands and everyday student life.

\section{Measures}

Academic Hardiness was assessed using the R-AHS (Benishek et al., 2005). The RAHS is a self-report questionnaire of 40 items. Participants rated each item on a 4point Likert scale: 1 =absolutely disagree, 2=disagree, 3=agree, 4=absolutely agree. High score indicates undergraduates with a highest level of academic hardiness. The R-AHS includes 3 scales: (a) commitment (e.g. "Work hard in the class even if bored"), (b) control (e.g. "I'm able to push away negative thoughts when not performing well in class") and (c) challenge (e.g. "Enjoy the challenge of difficult class"). Thirteen items are negatively formulated and thus reversed-scored.

\section{Adaptation progress}

The R-AHS was translated to Greek following the International Test Commission (ITC) guidelines for test adaptation (Hambleton, 2001). Items of the original version were translated into Greek by two bilingual speakers ant then another two bilingual speakers back-translated the scale to English. After the back translations minor translation discrepancies were found and minor vocabulary adaptations were made. The final form of the Greek version of the R-AHS was pilot tested for a field test to a small sample of undergraduates $(\mathrm{N}=20)$ in the target population who examined it for appropriateness of the questions, clarity, language stability and wording. Also, each item of the scale was examined by a panel of researchers who were familiar with the

\footnotetext{
${ }^{59}$ In Greece the gender ration in social sciences schools is overwhelmingly in favour of women.
} 
literature and the research area. Minor changes were made, especially wording, at this point.

\section{Students' achievement}

Students' achievement was measured by a self-report question in which students were asked to give the grade point average (GPA) on the basis of the modules they had already attended. GPA as a measure of academic performance is widely recognized and has been used with many studies on personality and academic achievement, as a criterion variable (Karagiannopoulou \& Milienios, 2013a,b; Wagerman \& Funder, 2007). To check the accuracy of students' answer, they were also asked to answer a question about how they evaluated themselves objectively based on the marks, grades and comments they had been given in the course of their studies (self evaluation) (see Entwistle, 2009). Answers were ranged from 1 (badly) to 9 (very well). The high correlation between grade point average and self evaluation $(r=0.79)$ provides an element of reliable answers.

\section{Statistical analyses}

Given that the present study represented an initial attempt to examine the psychometric properties and the factor structure of the R-AHS in a different cultural context and a different educational setting, exploratory factor analysis (EFA) was employed. Varimax rotation was conducted as the factors were not expected to be correlated. Principal Component Analysis (PCA) was carried out. PCA was also used by Benishek et al. (2005) as a method for exploratory analysis since their goal was to identify a small number of coherent dimensions that best represented their data. Five criteria were used to determinate the number of factors to retain (a) the amount of variance explained by each factor (2) factor structure coefficients of 0.40 or greater, (3) the scree test, (4) eigenvalues (greater than 1.0), and (5) the conceptual meaningfulness of the factors. Internal consistency of the factors was tested with the alpha reliability test and split half test.

Pearson's correlation coefficients between commitment, control and challenge and total hardiness was performed for each of the three years of studying. Furthermore we calculated one-way Anova statistical test to investigate how the GPA varied among undergraduates with low, medium and high scores on academic hardiness. 
One-way Anova was also used to identify differences in academic hardiness reported by students in different years of study.

\section{RESULTS}

\section{Descriptive statistics}

The means, standard deviations and internal consistencies of the Greek version of the R-AHS subscales are presented in Table 1. Internal consistency coefficients (Cronbach's alphas) are satisfactory for commitment, control and challenge, varying between .77 and .82 .

Table 1: Number of items, means, item-total correlation, a-cronbach and split-half of the Greek version of the Revised Academic Hardiness Scale.

\begin{tabular}{lcccccc}
\hline \multicolumn{1}{c}{ Factors } & $\begin{array}{c}\text { Number } \\
\text { of items }\end{array}$ & M & Std & $\begin{array}{c}\text { Item-total } \\
\text { correlation }\end{array}$ & $\begin{array}{c}\text { a- } \\
\text { cronbach }\end{array}$ & $\begin{array}{c}\text { split- } \\
\text { half }\end{array}$ \\
\hline & & & & & & \\
Commitment & 17 & 2.87 & .34 & $.32-.58$ & .82 & .69 \\
Control & 10 & 2.74 & .51 & $.40-.68$ & .80 & .73 \\
Challenge & 11 & 2.27 & .38 & $.35-.67$ & .77 & .75 \\
\hline
\end{tabular}

\section{Results from exploratory factor analysis (EFA)}

Initially, the factor analysis of the items of the scale was carried out. The KaiserMeyer-Olkin's measure of sampling adequacy (.86) and the Bartlett's sphericity test $\left(X^{2}=7292.18\right)$, suggest the possibility of extracting more than one factor from the items on the R-AHS. Concerning the overall sample $(\mathrm{N}=478)$ factor analysis produced a three factor solution (based on the eigenvalues and the scree-plot) which accounted $38.65 \%$ of the total variance. The factor pattern matrix of loadings is shown in Table 2. Three of the items ("Increase my effort when not performing well in class", "Get help when not receiving the grades I want" and "Don't ask for help when challenged academically"), loaded on the first factor, commitment, while in the original study (Benishek et al., 2005) they loaded on the second factor (control). Also two items ("With hard work I can meet my educational goals" and "Seek help from teachers when performing poorly") had loadings lower than .30. These two items were not included in the Greek version of the R-AHS. The correlation analysis among 
factors evidenced weak correlation among the three factors (Table 3). The factors of the Greek version of the R-AHS were independent of each other.

Table 2: Factor pattern coefficients for the three factor varimax solution for the R-AHS using principal components analysis.

\begin{tabular}{|c|c|c|c|c|c|}
\hline \multirow[b]{2}{*}{ No } & \multirow[b]{2}{*}{ Questions } & \multicolumn{3}{|c|}{ Factors } & \multirow[b]{2}{*}{$\mathbf{h}^{2}$} \\
\hline & & 1 & 2 & 3 & \\
\hline 18 & Put effort into all classes in the university & .69 & & & .48 \\
\hline 7 & Work hard for my grades in the university & .68 & & & .47 \\
\hline 39 & Work hard in the class even if bored & .68 & & & .46 \\
\hline 31 & Do best work regard less of the class & .66 & & & .44 \\
\hline 24 & Try hard in the class regardless of my interest level & .64 & & & .42 \\
\hline 2 & $\begin{array}{l}\text { Cut back extracurricular activities to improve my } \\
\text { grades }\end{array}$ & .59 & & & .38 \\
\hline 1 & Don't take student work seriously & .57 & & & .33 \\
\hline 14 & Consider self a serious student & .57 & & & .39 \\
\hline 28 & University is top priority & .52 & & & .27 \\
\hline 25 & $\begin{array}{l}\text { Increase my effort when not performing well in } \\
\text { class }\end{array}$ & .47 & & & .27 \\
\hline 8 & Won't go out with friends if I need to study & .44 & & & .24 \\
\hline 15 & $\begin{array}{l}\text { Doing well in university is as important to me as to } \\
\text { my parents }\end{array}$ & .41 & & & .19 \\
\hline 37 & Getting good grades isn't important to me & .39 & & & .15 \\
\hline 3 & Get help when not receiving the grades I want & .32 & & & .10 \\
\hline 32 & Don't ask for help when challenged academically & .30 & & & .14 \\
\hline 21 & $\begin{array}{l}\text { Good at calming self when anxious about my ability } \\
\text { to do well on a test or project }\end{array}$ & & .81 & & .66 \\
\hline 26 & $\begin{array}{l}\text { Good at decreasing stress if not performing well } \\
\text { academically }\end{array}$ & & .78 & & .62 \\
\hline 17 & $\begin{array}{l}\text { I am able to push away negative thoughts when } \\
\text { not performing well in class }\end{array}$ & & .77 & & .61 \\
\hline 10 & $\begin{array}{l}\text { Can manage stress from difficult course work in } \\
\text { healthy ways }\end{array}$ & & .77 & & .59 \\
\hline 30 & Able to stay calm when not doing well on a test & & .76 & & .60 \\
\hline 22 & I doubt my ability if I perform poorly & & .60 & & .39 \\
\hline 6 & Can stay calm and learn from mistakes & & .58 & & .34 \\
\hline 11 & Poor grades make me feel like giving up & & .50 & & .31 \\
\hline 36 & $\begin{array}{l}\text { Am miserable to be around when I receive a } \\
\text { disappointing grade }\end{array}$ & & .48 & & .32 \\
\hline 34 & Bad grades put me in a bad mood for the day & & .46 & & .25 \\
\hline 9 & Know when to ask for help & & .31 & & .20 \\
\hline 13 & $\begin{array}{l}\text { Don't ask questions when confused about } \\
\text { schoolwork }\end{array}$ & & .30 & & .26 \\
\hline 20 & Prefer easy classes so I get good grades & & & .79 & .63 \\
\hline 27 & Take classes I think will be easy & & & .79 & .63 \\
\hline
\end{tabular}


29 Take classes that require the least amount of work 72

16 Prefer to take classes to get an "easy A"

5 Avoid enrolling in difficult classes

23 Willing to take difficult class and risk getting a bad

12 Don't avoid taking difficult classes

40 Enjoy the challenge of a difficult class

33 Take difficult classes because I know that they will benefit me in long run

35 Intentionally seek out difficult classes

38 Is foolish to risk lowering CPA by choosing difficult classes even if they are interest to me

K.M.O. $=.86$

Bartlett test of Spericity $=7292.18, p<.05$

$\%$ account of variance

Eigenvalues

5.17

5.16

5.12

Note: Items No 1,13,32,37,16,20,29,27,37,11,36,34,22 are inversely scored

Note: Factor $1=$ commitment, Factor $2=$ control, Factor $3=$ challenge

\section{Academic hardiness and GPA across the years of study.}

Subscales were computed for the three factors that emerged from the factor analysis by summing the values of the items corresponding to the factor solution. Table 3 presents bivariate correlations of the three factors and the total academic hardiness with GPA in the three different university years. Commitment and the overall academic hardiness scores were correlated statistically significantly with GPA. More specifically, the overall academic hardiness score was positively correlated with the GPA reported by the third $(r=.24)$ and fourth year students $(r=.28)$. Commitment was positively correlated with the GPA reported by the second $(r=.45)$ and the fourth year students $(r=.46)$, whereas control was correlated with year three $(r=.20)$ GPA.

Table 3: Correlations between commitment, control, challenge and GPA across the years of study.

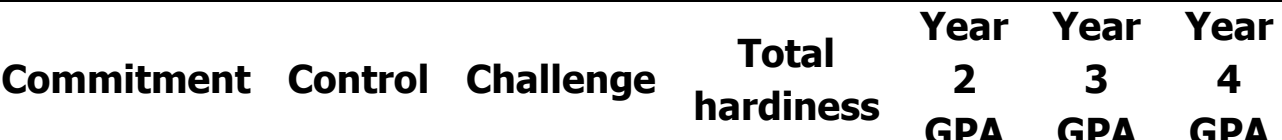

\begin{tabular}{lllllll}
\hline Commitment & .02 & $.12^{*}$ & $.48^{* *}$ & $.45^{* *}$ & .09 & $.46^{* *}$ \\
Control & & $.27^{* *}$ & $.75^{* *}$ & -.06 & $.20^{*}$ & -.05 \\
Challenge & & & $.69 * *$ & -.13 & .12 & .13
\end{tabular}


Total

hardiness

$.07 .24 * * \quad .28 * *$

$\begin{array}{lllll}\text { Total } & .36 * * & .04 & .05 & .20 * *\end{array}$

$* \mathrm{p}<.05$

To explore further the relationship between academic hardiness and GPA, we grouped students in three categories, high, medium and low according to their scores on academic hardiness, and on the three subscales (commitment, control and challenge). The one-way Anova statistical test revealed that undergraduates with a high score on Academic Hardiness had the higher GPA $\left[F_{(2,650)}=3.98, p=.019\right]$ (Figure 1). Both correlation analyses and one-way Anovas' analysis provided a strong support for the convergent validity of the Greek version of the "Academic Hardiness Scale", revealing relationships between GPA and academic hardiness.

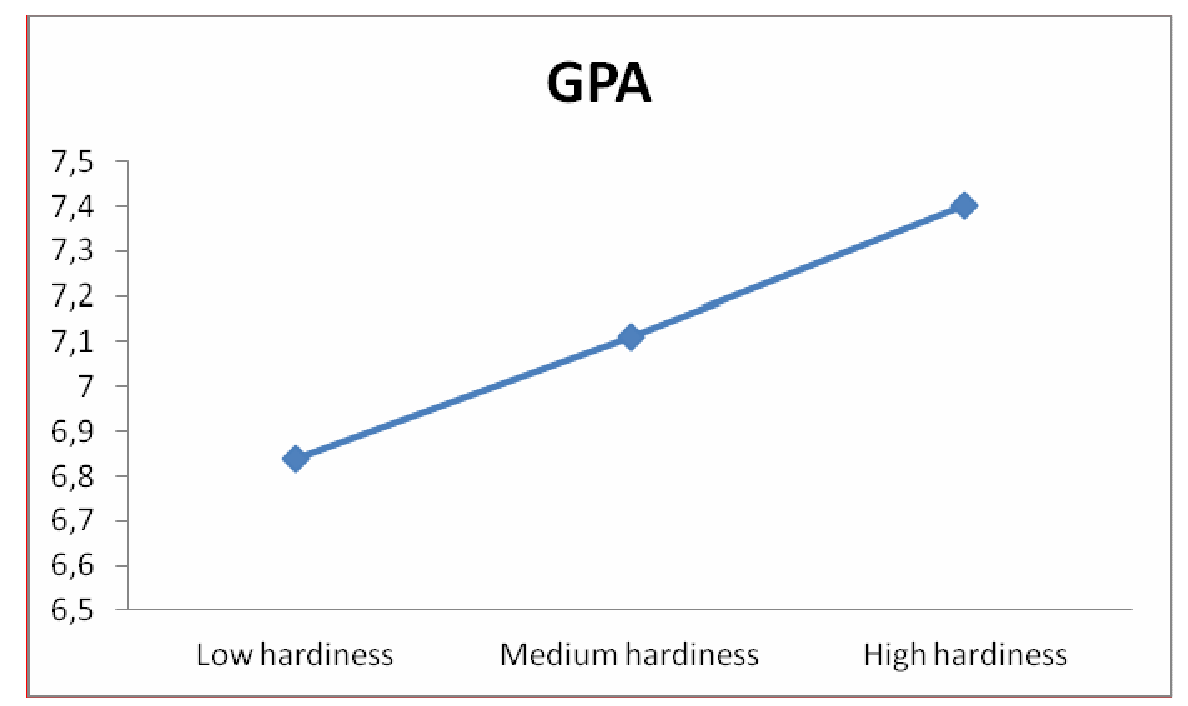

Figure 1: Differences through levels of hardiness in GPA

\section{Differences in academic hardiness reported by students in different years of study}

One-way Anovas' results (using Sidak post-hoc test) indicated that second year students scored higher in commitment, challenge and in the total academic hardiness score, comparing to their third and fourth year counterparts (Table 4). Table 4 also shows that getting through the years of study (second, third and fourth) students' commitment, challenge and academic hardiness tend to reduce. 
Table 4: Differences through years of study in commitment, control, challenge and academic hardiness.

\begin{tabular}{|c|c|c|c|c|c|}
\hline & $\begin{array}{c}2^{\text {nd }} \\
(\mathrm{N}=107) \\
M \text { [Std] }\end{array}$ & $\begin{array}{c}\text { Year of study } \\
3^{\text {rd }} \\
\begin{array}{c}(\mathrm{N}=110) \\
M[S t d]\end{array}\end{array}$ & $\begin{array}{c}4^{\text {th }} \\
(N=261) \\
M[S t d]\end{array}$ & $\mathbf{F}$ & $\mathbf{p}$ \\
\hline Commitment & $3.02[.36]^{1}$ & $2.9[.34]$ & $2.9[.39]$ & 4.49 & .012 \\
\hline Control & $2.74[.34]$ & $2.78[.38]$ & $2.71[.40]$ & 1.33 & .265 \\
\hline $\begin{array}{l}\text { Challenge } \\
\text { Academic }\end{array}$ & $2.15[.33]^{2}$ & $2.12[.32]^{3}$ & $2.01[.34]^{2,3}$ & 7.69 & .001 \\
\hline hardiness & $2.64[.19]^{2}$ & $2.60[.22]^{3}$ & $2.54[.26]^{2,3}$ & 6.70 & .001 \\
\hline
\end{tabular}

\section{DISCUSSION}

The goal of the present study was to investigate the psychometric properties of the Greek version of the revised Academic Hardiness Scale (R-AHS) in the Greek educational content and to investigate relationships between academic hardiness, achievement and the year of study in Greek undergraduates. The initial scale included 40 items. After the translation into Greek, the examination of the wording and the clarity of the scale, results from principal components analysis revealed a three-factor solution (38 items). The current findings are largely supportive to academic hardiness theory (Benishek et al. 2005), based on the initial Kobasa's (1979) three dimension model for hardiness theory. The accepted to high level of internal consistency, based on the total sample, indicates that the survey instrument and its subscales are reliable and can be used to assess university students' academic hardiness.

The psychometric characteristics of the R-AHS presented in the study support those reported in the original study (Benishek et al., 2005) concerning the following: (a) a clear three-factor solution (b) a similar amount of variance [33\% in Benishek et al. (2005) study and $38.65 \%$ in our study] (c) similar Cronbach's a coefficients [both studies give high and satisfactory alphas]. However, there are some differences between the two studies. First, two items in our study gave loadings <.30. Benishek et al. (2005) reported that these items had moderate to high loadings on the second 
factor (control). Also three items in our study loaded on the first factor (commitment), whereas these items in Benishek et al. (2005) study loaded on the second factor (control). We assume that these differences could be due to differences in study population, domain or culture differences.

The present study also provides preliminary evidence of convergent validity of the Greek version of the "Academic Hardiness Scale". Results indicate positive correlations of commitment and total hardiness with undergraduates' GPA. Also, undergraduates with high scores on Academic Hardiness reported high GPA, supporting the suggestion that academic hardiness is a central factor in university performance and academic success (Maddi, 2006; Maddi et al., 2011). Academic hardiness possibly provides the courage and motivation to students to cope with exam demands and the stress possibly raised in the academic context (Amponsah, 2010; Rodotham, 2008). The positive correlation of hardiness with GPA is in line with Maddi et al. (2011) study and also with Sheard and Golby (2007) study which indicated that students who are high on hardiness achieve a higher GPA and that students scoring high on the commitment had a higher GPA. The present study also revealed that challenge had a weak and no statistically significant correlation with GPA. This result is inconsistent with Benishek et al. (2005) study who found a significant correlation between GPA scores and challenge. However, they are in line with a later study (Sheard \& Golby, 2007) which indicated that challenge had no significant correlation with GPA. We assume that those undergraduates who achieved a higher GPA appeared to do so in spite, and not because, of behavioral manifestations of challenge.

The relationships between GPA and the dimensions of hardiness appeared to vary across the year of study. In contrast with Sheard and Golby (2007), our study indicated a positive correlation of control with GPA only for the third year students. Possibly, in this year students have become responsible for their learning and have control over their studies which may lead to better grades. Such a suggestion is supported by a recent study in which $3^{\text {rd }}$ year students who reported a deep/strategic approach to learning gave the highest GPA (Karagiannopoulou \& Milienos, 2013a).

Also, the present study indicates that students become less hardy in terms of commitment and challenge across the years of study. Undergraduates at a later stage of their studies ( $4^{\text {th }}$ years) reported less commitment to their work and less 
challenge comparing to younger students. Possibly, in the final year of studies exams loom and performance goals dominate over learning goals (Gow \& Kember, 1990; Karagiannopoulou \& Milienos, 2013a). Focus on success in the exams makes unlikely for them to treat failure as challenge. Taking in mind that university students experience a variety of stress-related situations (Hystad et al., 2009; Robotham, 2008; Struthers, Perry \& Menec, 2000) in a competitive, pressurized and high workload academic environment, one can hypothesize that such experiences have an adverse effect on students' commitment and challenge. Future studies focusing on relations between academic hardiness and students' experiences of the academic environment may illuminate such a suggestion.

Taking into consideration that there is little evidence, to date, for the moderating role of academic hardiness on students' achievement and of the role of hardiness on students' adjustment to university life (Sheard \& Golby, 2007), the variety of relations between GPA and academic hardiness over the years of study, suggested in the present study, indicate academic hardiness as a possible moderator for students' achievement. However, the study has some potential limitations. Given evidence that validation of a scale is an ongoing process where evidence needs to be collected from a number of sources and samples to strengthen and support the validity of scale scores (Messick, 1995), more studies should be conducted to examine additional validity aspects of the R-AHS. The study also represents students' views from a specific department, thus the conclusions are mostly applicable to those students. Nevertheless, links to findings may enable us to raise issues for further research.

Future studies using the Greek version of the R-AHS may shed light on the mediating role of academic hardiness and its components on students' learning and on academic achievement over the years of study. Path analysis models may reveal such links. They may test the effect of academic hardiness (first stage, presage factor) on approaches to learning (second stage, process factor) and then the effect of approaches on achievement (third stage, outcome). Such models will test academic hardiness as state or trait variable (Chamoro-Premuzic, \& Furnham, 2008; Duff, Boyle, Dunleavy, \& Ferguson, 2004; see also Karagiannopoulou and Milienos, 2013b). 
Replication also of the present study with a large sample of students from different university departments would lend support to the current findings and to the psychometric qualities of the particular scale. The use of samples of convenience may introduce possible external validity threats (Lowe, Grumbein, \& Raad, 2011). Also, future studies should examine possible variations of academic hardiness in different learning environments. Academic hardiness may not be a general feature of personality, but rather a specific inclination as how undergraduates react in particular circumstances. Taking this into account, future studies should investigate the influence of academic context on students' academic hardiness challenging the nature of this theoretical construct as state or trait variable.

Eventually, keeping in mind that (a) grades have emerged as a key stressor in studies of academic stress literature (Struthers et al., 2000) (b) students high on hardiness seem to be less affected by the stress associated with obtaining good grades (Hystad et al., 2009) and (c) also the relationship identified in the present study between academic hardiness and academic achievement, we suggest the importance of intervention programmes, possible in line with Khoshabas' and Maddi (1998) work, to enhance academic hardiness. Students high in academic hardiness are likely to experience less academic stress which may lead to better grades. These programmes should also take into account the differences in particular dimensions of academic hardiness across the years of study and the creation of learning environments that promote academic hardiness. 


\section{REFERENCES}

Amponsah, M. (2010). Non U.K. university students stress levels and their coping strategies. Educational Research, 1(4), 88-98.

Benishek, L., Feldman, J., Shipon, W., Mecham, S., \& Lopez, F. (2005). Development and evaluation of the revised academic hardiness scale. Journal of Career Assessment, 13, 59-76.

Benishek, L., \& Lopez, F. (2001). Development and initial validation of academic hardiness scale. Journal of Career Assessment, 9, 333-352.

Chamorro-Premuzic, T., \& Furnham, A. (2008). Personality, intelligence and approaches to learning as predictors of academic performance. Personality and Individual Differences, 44, 1596-1603.

Cole, M., Field, H., \& Harris, S. (2004). Student learning motivation and psychological hardiness: Interactive effects on students' reaction to a management class. Academy of Management Learning and Education, 3(1), 64-85.

Duff, A., Boyle, E., Dunleavy, K., \& Ferguson, J. (2004). The relationship between personality, approach to learning and academic performance. Personality and Individual Differences, 36, 1907-1920.

Entwistle, N. J. (2009). Teaching for understanding at university: Deep approaches and distinctive ways of thinking. Basingstoke: Palgrave Macmillan.

Florian, V., Milkulincer, M., \& Taubman, O. (1995). Does hardiness contribute to mental health during a stress real life situation? The roles of appraisal and coping. Journal of Personality and Social Psychology, 68, 687-695

Gow, L. \& Kember, D. (1990). Does higher education promote independent learning? Higher Education, 19, 307-322

Golightly, T. (2007). Defining the components of academic self efficacy in Navajo Indian high school students. Unpublished doctoral dissertation. Department of Counseling Psychology and Special Education, Brigham Young University.

Green, S., Grant, A., \& Rynsaardt, J. (2007). Evidence based life coaching for senior high school students: Building hardiness and hope. International Coaching Psychology Review, 2(1), 24-32.

Hambleton, R.K. (2001). The next generation of the ITC test translation and adaptation guidelines. European Journal of Psychological Assessment, 17(3), 164-172. 
Hystad, S., Eid, J., Laberg, J., Johnsen, B., \& Bartone, P. (2009). Academic stress and health: Exploring the moderating role of personality hardiness. Scandinavian Journal of Educational Research, 53(5), 421-429.

Kamtsios, S., \& Karagiannopoulou, E. (2011). Psychometric characteristics of the "Academic Hardiness Scale" in a Greek sample: a pilot study. Scientific Annals, School of Psychology, Aristotle University of Thessaloniki, 8, 67-88.

Karagiannopoulou, E, \& Milienos, F. (2013a). Exploring the relationship between experienced students' preference for open and closed-book examinations, approaches to learning and achievement. Education Research and Evaluation: An International Journal on Theory and practice. http://dx.doi.org/10.1080/13803611.2013.765691.

Karagiannopoulou, E, \& Milienos, F. (2013b). Testing two path models to explain relationships between experiences of the learning environment, approaches to learning and achievement. Educational Psychology, accepted.

Karimi, A., \& Venkatesan, S. (2009). Mathematics anxiety, mathematics performance and academic hardiness in high school students. International Journal of Educational Sciences, 1(1), 33-37.

Khoshaba, D.M., \& Maddi, S. (1998). Early experiences in hardiness development. Consulting Psychology Journal, 51, 106-116.

Kinder, R. (2008). Development and validation of the student's activation measure. Unpuplished Doctoral Dissertation, Vanderdilt University, Tennessee.

Kobasa, S. (1979). Stressful life events, personality and health: An inquiry into hardiness. Journal of Personality and Social Psychology, 37, 1-11.

Kobasa, S., Maddi. S., \& Kahn, S. (1982). Hardiness and health: A prospective study. Journal of Personality and Social Psychology, 42, 168- 177.

Kobasa, S., Maddi, S, Puccetti, M., \& Zola, M. (1985). Effectiveness of hardiness, exercise and social support as resources against illness. Journal of Psychosomatic Research, 29(5), 525-533.

Lifton, D., Seay, S., McCarly, N., Olive-Taylor, R., Seeger, R., \& Bighee, D. (2006). Correlating hardiness with graduation persistence. Academic Exchange Quarterly, 10, 277-282.

Lifton, D, Seay, S., \& Bushke, A. (2000). Can student's hardiness serve as an indicator of likely persistence to graduation? Baseline results from a longitudinal study. Academic Exchange Quarterly, 4, 73-81. 
Lowe, P., Grumbein, M., \& Raad, J. (2011). Examination of the psychometric properties of the test anxiety scale for elementary student's scores. Journal of Psychoeducational Assessment, 29(6), 503-514.

Maddi, S. (2006). Hardiness: The courage to grow from stresses. The Journal of Positive Psychology, 1(3), 160-168.

Maddi, S. (2005). On hardiness and other pathways to resilience. American Psychologist, 60(3), 261-272.

Maddi, S. R. (2002). The story of hardiness: Twenty years of theorizing, research, and practice. Consulting Psychology Journal, 54, 175-185.

Maddi, S., Harvey, R., Khoshaba, D., Fazel, M., \& Resurreccion, N. (2011). The relationship of hardiness and some other relevant variables to college performance. Journal of Humanistic Psychology, 52(2), 190-205.

Messick, S. (1995). Validity of psychological assessment: Validation of inferences from person's responses and performances as scientific inquiry into some meaning. American Psychologist, 50, 741-749.

Paleologou, A., \& Dellaporta, A. (2010). Hardiness vs alienation personality construct essentially explains burnout proclivity and erroneous computer entry problems in rural Hellenic hospital labs. International Journal of Human and Social Sciences, 5, 438-453.

Robotham, D. (2008). Stress among higher education students: towards a research agenda. Higher Education, 56, 735-746.

Sheard, M. (2009). Hardiness, commitment, gender and age differentiate university academic performance. British Journal of Educational Psychology, 79(1), 189204.

Sheard, M., \& Golby, J. (2007). Hardiness and undergraduate academic study: The moderating role of commitment. Personality and Individual Differences, 43, 579588.

Struthers, W., Perry, P., \& Menes, H. (2000). An examination of the relationship among academic stress, coping, motivation and performance in college. Research in Higher Education, 41, 581-592.

Wagerman, A., \& Funder, D. (2007). Acquaintance reports of personality and academic achievement: a case for conscientiousness. Journal of Research in Personality, 41, 221-229. 
